\title{
Research on the Effects of 5-HT1A Receptor in Hippocampal CA1 Region in the Cognition of PTSD Rats
}

\author{
Ling Lin ${ }^{1, a}$ Guoliang Liu ${ }^{2, b}$ Yinpo Zhang ${ }^{3, c}$ \\ ${ }^{1}$ Luohe Medical College, Luohe, Henan, China, 462002 \\ aemail, ${ }^{\text {bemail, }}{ }^{\mathrm{c} e m a i l,}$
}

Keywords: PTSD, Hippocampal, 5-HT1A Receptor, Spatial Memory

\begin{abstract}
Objective: Investigate the expression of 5-HT1A receptor in CA1 area of hippocampus of posttraumatic stress disorder (PTSD) rats and to explore the function of 5-HT1A receptor in the cognitive behavior of PTSD rats. Methods: 72 healthy adult SD rats were randomly divided into 4 groups: A (control group), $\mathrm{B}$ (model group), $\mathrm{C}$ (control +agonist group )and $\mathrm{D}$ (model + agonist group), with 18 rats in each group. The rats in $\mathrm{B}$ and $\mathrm{C}$ groups were constructed with continuous single stimulation (SPS) to construct the PTSD model rats. 2 days after the model was completed, the CA1 of the hippocampus was located under the Stereotaxic instrument. The rats of B and C groups were injected with 5-HT1A receptor agonist 8-OH-DPAT, A and B group rats were injected with equal amount of normal saline, and the dose was $0.3 \mathrm{mg} / \mathrm{kg}$. Morris water maze (MWM) was used to test the learning and memory ability in different groups of rats, The expression of 5-HT1A and 5-HT1A protein in hippocampus was examined by immunohistochemistry and immunofluorescence and Western Blot. Results: It was showed in the MWM experiment that the latency of rats in searching for the underwater platform in group $\mathrm{C}$ rats was significantly shorter compared with the group $\mathrm{A}(\mathrm{P}<0.01), \mathrm{B}$ and $\mathrm{C}$ group were increased $(\mathrm{P}<0.01)$. Compared with group $\mathrm{B}$, group $\mathrm{D}$ rats escape the latency was significantly prolonged $(\mathrm{P}<0.01)$. The expression of $5-\mathrm{HT} 1 \mathrm{~A}$ receptor in CA1 region of hippocampal by immunohistochemistry and immunofluorescence and Western Blot experiments all showed that, Compared with the group A, the other 3 groups were significantly increased $(\mathrm{P}<0.01)$, Compared with the group $\mathrm{B}$, the group $\mathrm{D}$ was significantly increased $(\mathrm{P}<0.01)$, neverthelessly, there was no significant difference between the B group and the $\mathrm{C}$ group $(\mathrm{P}>0.05)$. Conclusion: The spatial memory impairment in rats with PTSD maybe associated with the increase of the expression of 5-HT1A receptor in the CA1 region of hippocampus.
\end{abstract}

\section{Introduction}

Posttraumatic stress disorder (PTSD) is a mental disorder characterized by cognitive dysfunction, which is delayed and last for a long time after an unusual threat or disaster. $[1,2]$ There is a clear memory about the unusual threat or disaster or totally forget it. The function of accepting and storing new information is impaired [3]. PTSD has become a serious threat to human health and even life and it is one of the important diseases, but its pathogenesis is not very clear. There are a lot past research on 5-HT and its receptors and stress disorder $[4,5]$, the results of different researches are different, and the conclusions are even diametrically opposed to each other. This experiment wants to further reveal the role of 5-HT1A receptors in the pathogenesis of PTSD. This experiment using SPS (Single Prolonged Stress) method to build PTSD rat model [6], combine 5-HT1A receptor agonist, through the behavioral theory to detect the spatial memory of rats, immunohistochemistry, immunofluorescence and through the Western Blot test to detect the hippocampal CA1 5-HT1A receptor expression, and explore the role of 5-HT1A in cognitive behavior of PTSD rats.

\section{Materials and Method}

Material. 72 adult male Sprague-Dawley (SD) rats, SPF grade, body weight 180-220g, purchased 
from Hunan Slack Jingda Experimental Animal Co., Ltd., Certificate No .: SCXK (Xiang) 0003. The rats were randomly divided into 4 groups: A group (normal control group), B group (model group), C group (normal + agonist group) and D group (model + agonist group), each 18. Animal feeding environment: ventilation, natural light, $12 \mathrm{~h}$ light $/ 12 \mathrm{~h}$ dark. Room temperature: $22 \pm$ $1{ }^{\circ} \mathrm{C}$.

HRP-labeled goat anti-rabbit glycerin secondary antibody, FITC-labeled goat anti-rabbit secondary antibody, Triton X-100, anti-rabbit anti-rabbit IgG, anti- BSA, etc. (all purchased in Biyun days Biotechnology Co., Ltd.).

Experimental instrument. Morris water maze (Beijing Academy of Medical Sciences Institute of drug development); fluorescence microscope (OLYMPUS, BX53TR-32FB3-F01), frozen slicer (OLYMPUS), rat stereotaxic apparatus (Anhui Zhenghua Biological Equipment Co., Ltd.), Micro-injection pumps are (Chengdu Thailand UNITA Technology Co., Ltd.), high-speed refrigerated centrifuge (Germany Beckman).

Method. Preparation of the animal model of PTSD. According to the method of literature 6, rats of group B and D were treated with the following steps: imprisonment for 2 hours; forced swimming for 20 minutes (water depth: $40 \mathrm{~cm}$, water temperature: $25{ }^{\circ} \mathrm{C}$ ); having a rest for $15 \mathrm{~min}$, ether anesthesia until loss of consciousness. All groups of animals without disturbing feeding, conventional feeding and drinking water, feeding temperature of $22 \pm 1{ }^{\circ} \mathrm{C}$.

Animal surgery and administration. The rats were anesthetized by intraperitoneal injection of $10 \%$ chloral hydrate $(300 \mathrm{mg} \bullet \mathrm{kg}-1)$, fixed on a stereotaxic apparatus, and cut the head skin and expose the dura mater. The rats were injected with 5-HT1A receptor agonist 8-OH-DPAT, group A (group A), group C (group A), group A (group D) And group B, the same dose of saline, the dose is $0.3 \mathrm{mg} / \mathrm{kg}$, all operations are carried out under sterile conditions.

Behavioral test. Rats in each group after treatment with 24 hours Morris water maze test. Morris water maze is a circular basin with a diameter of $125 \mathrm{~cm}$ and a height of $50 \mathrm{~cm}$. The water depth is $40 \mathrm{~cm}$ and the water temperature is kept at $(25 \pm 1.0){ }^{\circ} \mathrm{C}$. The maze outside the training is kept constant during the training and the training last for 5 days, twice a day and each training interval $15 \mathrm{~min}$.

Immunohistochemistry experiment. After the water maze experiment, 6 rats in each group were subjected to immunohistochemistry. The rats were anesthetized with $10 \%$ chloral hydrate $(300 \mathrm{mg} /$ $\mathrm{kg}$ body weight) and perfused with $4 \%$ paraformaldehyde. The brain was fixed quickly, paraffin embedded, coronal slice, slice thickness $3 \mu \mathrm{m}$, washed with distilled water and washed with PBS for $5 \mathrm{~min}$. Three times, the antigen was repaired with citrate buffer, incubated in freshly prepared $0.3 \%$ $\mathrm{H} 2 \mathrm{O} 2$ solution for $10 \mathrm{~min}$ at room temperature, washed with PBS for 5 min, 5-HT1A polyclonal antibody (1: 500), incubated overnight at $4^{\circ} \mathrm{C}$, washed with PBS, immunohistochemical staining using SP immunohistochemistry kit, DAB color. The cytoplasm of the positive cells of immunohistochemistry was brown, and the average integral optical density of positive cells was measured by Image Proplus 6.0 image analysis software.

Immunofluorescence test. After the water maze test, take 6 rats in each group for immunofluorescence. After the rats were perfused, the brain was taken and placed in $4 \%$ paraformaldehyde solution overnight. After 30\% sucrose solution, the slices were sliced with constant temperature $\left(-20{ }^{\circ} \mathrm{C}\right)$, and the thickness was $30 \mu \mathrm{m}$. 1 slices of brain slices were rinsed with $0.3 \%$ TtitonX-100 for $2 \mathrm{~h}, 0.01 \mathrm{M}$ PBS for $5 \mathrm{~min} /$ time $\times 3$ times, $10 \%$ BSA for $1 \mathrm{~h}$ and $0.01 \mathrm{M}$ PBS for $5 \mathrm{~min} /$ time $\times 3$ times. Rabbit anti-5-HT1A polyclonal antibody (1: 500) was incubated at $4{ }^{\circ} \mathrm{C}$ overnight. After rewarming, 0.01M PBS was rinsed $5 \mathrm{~min} /$ time $\times 3$ times. (1: 1000) incubated at room temperature for $2 \mathrm{~h}$, washed with $0.01 \mathrm{M}$ PBS for $5 \mathrm{~min} /$ time $\times 3$ times, and sealed with anti-quencher. The film was observed under fluorescence microscope. The mean number of positive cells in the hippocampal CA1 area was detected by the software of IPP6.0.

Western blot test. The last 6 rats in each group were subjected to Western blot. The rats were sacrificed in the hippocampus. The protein concentration was determined by BCA protein quantification kit (Novagen). The protein concentration was adjusted to $110 \mu \mathrm{g} / \mathrm{ml}$. SDS-PAGE 
was performed for $10 \mathrm{~min}$ at $99{ }^{\circ} \mathrm{C}$. (5-HT1A antibody) was added to the nitrocellulose membrane for $5 \mathrm{~min}$ at room temperature for $1 \mathrm{~h}$. The cells were incubated with $10 \%$ fetal calf serum, $4 \mu 1$ of each sample, and $10 \mu 1$ of the sample was added to each well. Dumped to the first anti-TBST washing film 3 times, each $15 \mathrm{~min}$. Anti-rabbit anti-rabbit glycerol secondary antibody 1: 2000, shaking on the shaker at room temperature for $1 \mathrm{~h}$; discard the secondary antibody, TBST washing membrane 3 times, each 15 min; ECL light exposure imaging, IMAGE J software analysis Mean Optical Density (IOD).

Statistical analysis. All experimental data is analysis by the SPSS16.0 statistical software package for. Data were analyzed by normality test and variance homogeneity test. One-way analysis of variance (ANOVA) was used to compare the data between groups. The q-test (Newman-Keuls method) was used to compare between groups.

\section{Results}

Comparison of Escape Platform Latency of Rats in Different Groups. In the Morris water maze test, the latency of escape platform in group $\mathrm{C}$ was significantly shorter than that in group $\mathrm{A}$ (qd1 = $6.76, \mathrm{qd} 2=7.21, \mathrm{qd} 3=10.23, \mathrm{qd} 4=9.11, \mathrm{p}<0.01)(\mathrm{Qd} 1=10.07, \mathrm{qd} 2=8.77, \mathrm{qd} 3=22.51, \mathrm{qd} 4=$ $12.41, \mathrm{p}<0.01)$, and the difference between group D and group B was significant $(\mathrm{p}<0.01)$ (Fig. 1).

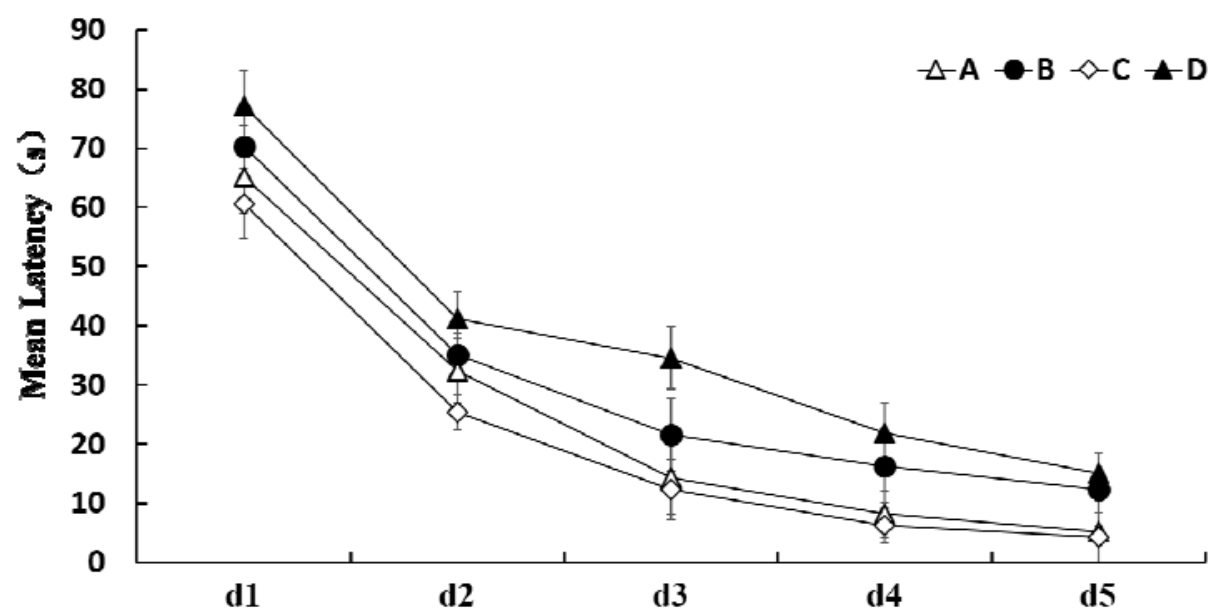

Fig.1 The escape latency of rat finding the hidden platform in Water Maze

Immunohistochemistry, the Expression of 5-HT1A Receptor in Hippocampal CA1 Region of Rats in Different Groups. The expression of 5-HT1A receptor in the hippocampal CA1 region, the other three groups was significantly increased (qA-B $=13.70, \mathrm{P}<0.05)$. The expression of 5-HT1A receptor in the cytoplasm was 5-HT1A receptor immunoreactive cells, $(\mathrm{P}<0.01)$. Compared with group $\mathrm{B}$, the expression of 5-HT1A receptor in hippocampal CA1 region of group D was significantly increased $(\mathrm{qB}-\mathrm{D}=8.99, \mathrm{p}<0.01)$, compared with group $\mathrm{B}(\mathrm{qA}-\mathrm{C}=12.84, \mathrm{qA}-\mathrm{D}=$ 22.69) ), but there was no statistically significant difference between group $\mathrm{B}$ and group $\mathrm{C}(\mathrm{P}>0.05)$ (Fig.2). 

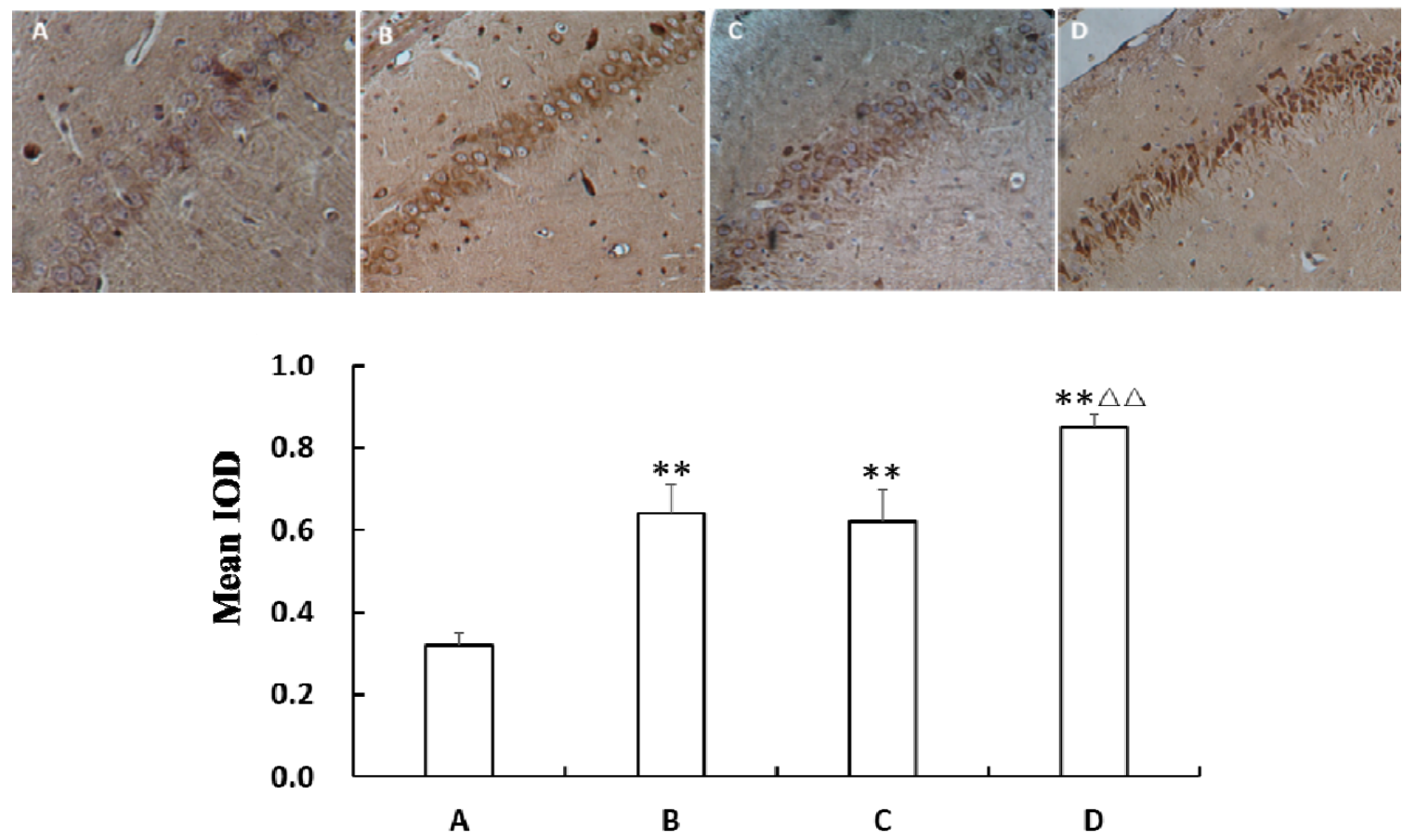

Fig.2 Immunohistochemistry photographs showing the expression of 5-HT1A receptor in different groups in hippocampal CA1 area (Bar=20 $\mu \mathrm{m}, * * \mathrm{P}<0.01 \mathrm{vs} \mathrm{A}, \triangle \triangle \mathrm{P}<0.01 \mathrm{vs} \mathrm{B}$ )

Immunofluorescence, the Expression of 5-HT1A Receptor in Hippocampal CA1 Region of Rats in Different Groups. The results showed that 5-HT1A receptor protein was observed in the cytoplasm of CA1 neurons in the hippocampus CA1 region, and 5-HT1A receptor positive cells in group A were weakly stained by fluorescence microscopy. The rest 3 The positive staining of 5-HT1A receptor positive cells in group D was stronger than that in group B. There was no significant difference between group B and group C (Fig.2)

The positive cell counts and integral optical density values of 5-HT1A receptor-positive cells in the hippocampal CA1 region of the other 3 groups were significantly higher than those in the A group $(\mathrm{qA}-\mathrm{B}=13.18, \mathrm{qA}-\mathrm{C}=11.95, \mathrm{qA}-\mathrm{D}=(\mathrm{P}<0.01)$. Compared with group $\mathrm{B}$, the optical density of group $\mathrm{D}$ was significantly higher than that of group $\mathrm{B}(\mathrm{qA}-\mathrm{B}=4.90, \mathrm{qA}-\mathrm{C}=5.36, \mathrm{qA}-\mathrm{D}=10.27$, $\mathrm{P}<(\mathrm{Q}=4.79, \mathrm{p}<0.05)$, integral optical density increased $(\mathrm{q}=5.36, \mathrm{p}<0.01)$, but between group $\mathrm{B}$ and group $\mathrm{C}$ was higher in cell count and integral optical density There was no statistically significant difference $(\mathrm{p}>0.05)$ (Fig.3)
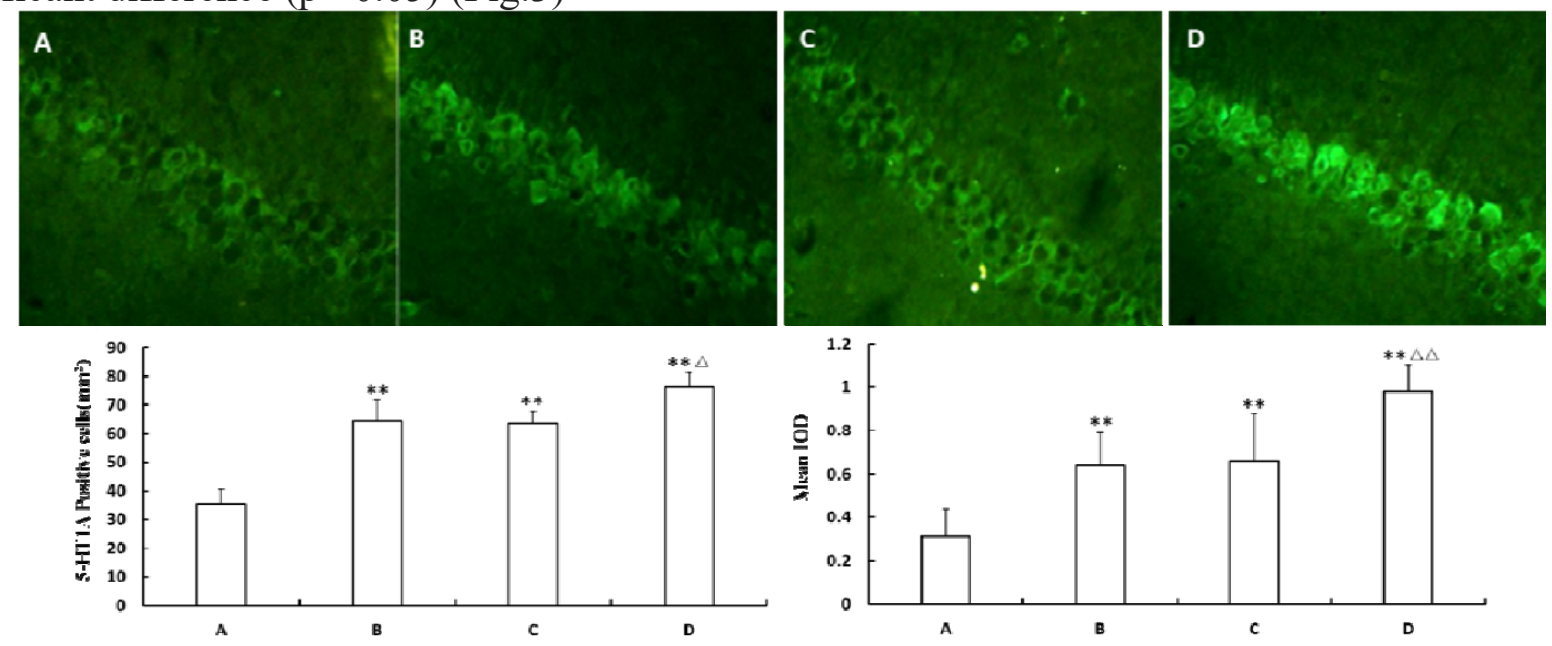

Fig.3 Immunofluorescence photographs showing the expression of 5-HT1A receptor in different groups in hippocampal CA1 area.(Bar $\left.=20 \mu \mathrm{m},{ }^{* *} \mathrm{P}<0.01 \mathrm{vs} \mathrm{A} ; \triangle \mathrm{P}<0.05, \triangle \triangle \mathrm{P}<0.01 \mathrm{vs} \mathrm{B}\right)$

Western Blot Results, the Expression of 5-HT1A Receptor in Hippocampal CA1 Region of Rats in Different Groups. Compared with group A, the expression of 5-HT1A receptor in 
hippocampal CA1 region of the other three groups was significantly increased $(\mathrm{q}=13.69, \mathrm{P}<0.01)$; compared with group $\mathrm{B}, 5-\mathrm{HT} 1 \mathrm{~A}(\mathrm{Q}=7.70, \mathrm{P}<0.01)$, but there was no significant difference between group $\mathrm{B}$ and group $\mathrm{C}(\mathrm{P}<0.05$, Fig.4).

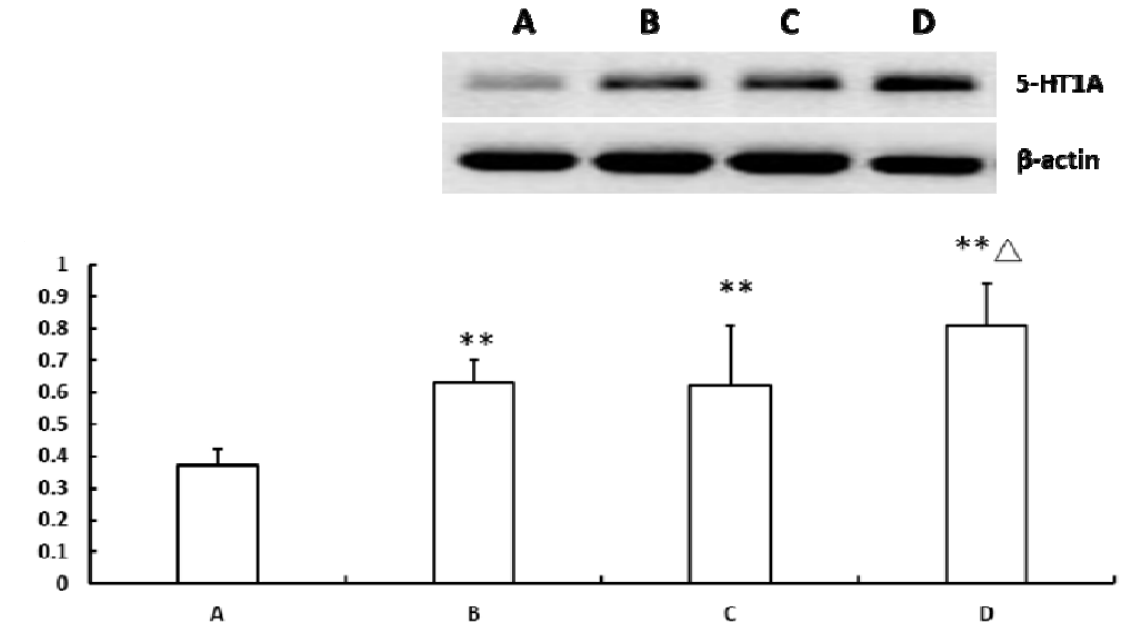

Fig.4 The expression of 5-HT1A in hippocampus in each group of rats $(* * \mathrm{P}<0.01 \mathrm{vs} \mathrm{A} ; \quad \triangle \mathrm{P}<$

$$
0.05, \triangle \triangle \mathrm{P}<0.01 \mathrm{vs} \mathrm{B}) .
$$

\section{Discussion}

Healthy organisms can adapt to complex changes in a variety of environmental factors, including the release of neurotransmitters, receptor expression changes to adapt to a variety of stress. If the adaptability declines, it will lead to a variety of diseases. PTSD is a typical stress disorder, stress adaptability may be closely related to brain 5-HT transmitter system and the 5-HT dysfunction may be an important etiology of PTSD basis [7,8]. In the known 5-HT receptor, 5-HT1A receptor and anxiety, depression and other mental illness is particularly closed [9].

In the present study, the PTSD rat model was constructed by SPS. The results showed that in the Morris water maze test, the time of looking for the underwater platform in group B was significantly longer than that in group A. It means the spatial memory ability of the rats decreased significantly, which accorded with the clinical features of PTSD, indicating that the model replication success.

In the present study, 5-HT1A receptor agonist 8-OH-DPAT $(0.3 \mathrm{mg} / \mathrm{kg})$ was administered to the hippocampal CA1 region of group $\mathrm{C}$ (normal + agonist), and the time to escape from the submerged platform latency was (Low dose of 5-HT1A receptor agonist 8-OH-DPAT) in rats treated with Lüttgen $\mathrm{M}$ and Haider S showed a significant improvement in rats of spatial memory, but high-dose, there is the opposite effect. The results indicated that 8-OH-DPAT, a low-dose 5-HT1A receptor agonist, could improve the learning and memory ability of normal rats.

However, in the PTSD model rats, the hippocampal CA1 area was given a 5-HT1A receptor agonist, 8-OH-DPAT, that is, rats in the D group (model + agonist group) We further detected the expression of 5-HT1A receptor in the hippocampal CA1 region of rats in the different groups of rats in order to explore the reason of the learning and memory ability.

Compared with group A, the expression of 5-HT1A receptor in the hippocampal CA1 region of the other three groups increased significantly. Compared with group B, the expression of 5-HT1A receptor protein in the immunohistochemistry, immunofluorescence and Western blot was significantly increased, The expression of 5-HT1A receptor in hippocampal CA1 region of group D was significantly increased, while there was no significant difference between group B and group C. The expression of 5-HT1A receptor in hippocampal CA1 region was increased, so the expression of 5-HT1 A receptor in hippocampal CA1 region of group B was significantly higher than that in group A $(\mathrm{P}<0.05)$. There was no significant difference in the expression of 5-HT1A between group B and group $\mathrm{C}$, but the expression of 5-HT1A in group B was not significantly different from that in group 
$\mathrm{B}$, but the expression of 5-HT1A was increased in group C The learning and memory ability of the rats in the $\mathrm{C}$ group was increased due to the stimulation of 5-HT1A, but increased in the $\mathrm{C}$ group.

5-HT1A receptors in the hippocampus were significantly increased in the D group as a result of the injection of 5-HT1A receptor agonist and stress stimuli in the hippocampus. This high dose of 5-HT1A The body's learning and memory ability of rats decreased significantly. 5-HT1A receptor activation, but also indirectly excited inhibitory neuronal activity of GABA neurons, and thus the activity of glutamatergic neurons were inhibited, and ultimately the learning and memory ability of rats. In addition, the stress stimulus will be reversible changes in the structure of central neurons, thereby changing the synaptic plasticity, thereby affecting the learning and memory function.

In conclusion, in stress-impaired rats, stress may lead to increased expression of 5-HT1A receptors in the hippocampus, leading to cognitive impairment in animals. This study provides a theoretical reference for the research and treatment of posttraumatic stress disorder.

\section{Acknowledgements}

Fund Project: Henan Province Science and Technology Department Natural Science Project (142300410431); Luohe City Youth Top Talent Funding Project; Henan Province Education Department Colleges and Universities Key Research Projects (15B180010)

\section{References}

[1] Citrome L, Stensbøl TB, Maeda K. The preclinical profile of brexpiprazole: what is its clinical relevance for the treatment of psychiatric disorders ? [J].Expert Rev Neurother, 2015,15:1219-29

[2] Sullivan GM, Ogden RT, Huang YY, et al.Higher in vivo serotonin-1a binding in posttraumatic stress disorder: a PET study with [11C]WAY-100635[J].Depress Anxiety, 2013,30:197-206.

[3] Liu D, Xiao B, Han F, et al.Changes in 5-HT1A receptor expression in the oculomotor nucleus in a rat model of post-traumatic stress disorder[J].J Mol Neurosci,2013,49:360-8.

[4] Luo FF, Han F, Shi YX.Changes in 5-HT1A receptor in the dorsal raphe nucleus in a rat model of post-traumatic stress disorder[J].Mol Med Rep, 2011,4 :843-7.

[5] Xie H, Han F, Shi X.Single-prolonged stress induce changes of CaM/CaMKIIa in the rats of dorsal raphe nucleus[J].Neurochem Res, 2012,37:1043-9.

[6] Liberzon I,Krstov M,Young EA. Stress-restress:effects on ACTH and fast feedback[J]. Psychoneuroendocrinology, 1997, 22 : 443-453.

[7] Dubrovsky B.The specificity of stress response to different nocuous stimuli:neurosteroids and depression[J].Brain Res Bull,2000,51:443-455.

[8] Finn DP,Marti O,Harbuz MS,et al.Behavioral,neuroendrocrine and neurochemical effects of the imidazoline $\mathrm{I} 2$ receptor selective ligand BU224 in naive rats and rats exposed to the stress of the forced swim test[J].BEHAVIO neuroendo Neurochem,2003,167:195-202.

[9] Brice Le François, Jeremy Soo,Anne M. Millar,et al.Chronic mild stress and antidepressant treatment alter 5-HT1A receptor expression by modifying DNA methylation of a conserved Sp4 site[J].Neurobiol Dis,2015,82: 332-341. 